\title{
A CADEIA PRODUTIVA DO LEITE: discussões sobre a crise do setor lácteo na região celeiro do estado do Rio Grande do Sul
}

\author{
Tiago Reginaldo ZAGONEL $^{1}$ \\ Dilson TRENNPOHL ${ }^{2}$ \\ Volmir Ribeiro do AMARAL ${ }^{3}$ \\ Licurgo Lauda BURMANN ${ }^{4}$ \\ Daniel Knebel BAGGIO 5
}

\begin{abstract}
${ }^{1}$ Mestrando em Desenvolvimento - UNIJUÍ. Graduado em Administração - UNIJUí. Bolsita UNIJUÍ. E-mail: tiagozagonel@ hotmail.com
\end{abstract}

${ }^{2}$ Doutor em Desenvolvimento Regional. Professor do DACEC/UNIJUI, integrante do Corpo Docente do Curso de Mestrado em Desenvolvimento da UNIJUI. dilson@unijui.edu.br

${ }^{3}$ Mestrando em Desenvolvimento - UNIJUÍ. Graduado em Filosofia - UNIJUÍ. volmirdoamaral@gmail.com

${ }^{4}$ Mestrando em Desenvolvimento - UNIJUÍ. Graduado em Agronomia - UFSM. licurgo.burmann@gmail.com

${ }^{5}$ Doutor em Contabilidade e Finanças / UNIZAR/Espanha. Professor do PPGDES/UNIJUÍ. baggiod@unijui.edu.br

Recebido em: 11/11/2015 - Aprovado em: 13/07/2016 - Disponibilizado em: 18/12/2016

\begin{abstract}
RESUMO
Esse estudo tem como objetivo socializar informações debatidas na região celeiro, as quais estão latentes no ambiente de crise que vive a cadeia produtiva do leite. As mudanças que estão acontecendo na cadeia impactam na produção, industrialização e comercialização e levam a um processo seletivo nos diferentes elos envolvidos. A pressão por uma otimização nos diferentes elos da cadeia fica visível na dinâmica do mercado, pois sem a profissionalização da cadeia visando diminuir os custos, aumentar a produção por animal e uma matéria-prima de qualidade, o produto não é competitivo e isso afeta diretamente todos os elos. Tendo um contato direto com a realidade, analisando de forma qualitativa e empírica, o estudo traz questões atinentes a produção, industrialização e comercialização de uma cadeia que mais emprega na área rural da região e cumpre um papel social e essencial na economia local e regional. O estudo conclui que sem a sinergia entre o ambiente institucional e organizacional, tais como o poder público, agricultores, laticínios locais, indústrias regionais, universidades, empresas de assistência técnica, segmentos de pesquisa, entre outras afins, não há possibilidade da região se desenvolver de forma endógena e sustentável.
\end{abstract}

Palavras-chave: Cadeia do Leite; Formalização; Agricultura; Associativismo.

\section{THE MILK PRODUCTION CHAIN: discussions on the dairy sector crisis in the region celeiro of Rio Grande do Sul state}

\begin{abstract}
This study aims to socialize information discussed in the Celeiro's region, which information are latent in the crisis environment that lives the milk production chain. Changes in the chain that are happening in the production, processing and marketing, lead to a selection process in the different links involved. The pressure for optimizing the different links in the chain is visible in the dynamics of the market, because without the professionalization of the chain in order to decrease costs, increase production per animal and raw material quality, the product is not competitive and it affects directly all links. Having direct contact with reality and analizing qualitative and empirically, the study brings pertaining to production issues, manufacture and sale of a chain that employs more in rural areas of the region and plays an essential role in social and local and regional economy.The study concludes that without the synergy between the institutional and organizational environment, such as the government, farmers, dairy local, regional industries, universities, technical assistance companies, research segments, among others the like, there is no possibility of the region to develop endogenous and sustainable manner.
\end{abstract}

Keywords: Milk Chain; Formalization; Agriculture; Association. 


\section{INTRODUÇÃO}

Há uma discussão acerca da problemática situação enfrentada pela cadeia produtiva do leite devido à descoberta de adulteração do leite desencadeada pelo Ministério Público - "Leite Compensado" que teve a sua primeira fase em Maio de 2013, onde transportadores foram presos. Posteriormente constatou-se que postos de resfriamento e indústrias também estariam envolvido na fraude.

A crise veio a afetar o conjunto do setor devido ao baixo índice de confiança do consumidor em consumir produtos lácteos e seus derivados, ocasionando excesso de oferta de leite no mercado, também devido a sazonalidade na diminuição do consumo nos primeiros meses do ano. Muitas empresas diminuíram drasticamente o valor pago ao produtor, outras não cumpriram suas obrigações com os produtores rurais, estando em situação questionável de lisura, sendo fechadas e enquadradas judicialmente por órgãos fiscalizadores e por credores, entre eles, produtores rurais.

A cadeia do leite não está normatizada atualmente quanto a sua comercialização, sendo que as empresas compram e produtores vendem havendo um acerto verbal das partes. $\mathrm{O}$ produtor sabe quanto recebeu pelo litro de leite vendido quarenta e cinco dias após a primeira de trinta entregas, correndo o risco de não receber o valor pela matéria-prima fornecida. A migração dos produtores de uma empresa para outra é uma estratégia desgastante a ambos, pois nos primeiros meses o produtor irá receber mais que a concorrência e depois reduz o valor como a anterior. Para a empresa não há uma garantia e estabilidade de recebimento e qualidade do produto devido à ausência de fidelização dos produtores, logo, não há interesse em investir em assistência técnica aos produtores que visam em primeiro lugar o melhor preço, sem levar em consideração o melhoramento em seus processos para uma melhor qualidade e, consequentemente, melhores preços.

Com o estudo na cadeia produtiva do leite, busca-se analisar a situação atual e perspectivas da mesma, onde alguns produtores estão buscando se profissionalizar na atividade leiteira, ampliando suas instalações, visando obter um produto de melhor qualidade. Os programas governamentais tem contribuído significativamente para tais investimentos e aprimoramento do setor lácteo. No entanto, alguns produtores tem a atividade leiteira como secundária, ou seja, apenas para ter uma renda complementar, sem interesse de expandir a sua produção.

Essa ausência de foco na atividade acaba corroborando com a "mão invisível" do mercado num processo de seleção dos maiores e mais preparados, que investiram e estão investindo em novas tecnologias, inovando seus processos, qualificando sua 
mão de obra, entre outras para ter ao final um produto com maior valor agregado, que no caso seria a quantidade maior de sólidos do leite e menor quantidade de bactérias entre outros contaminantes. Dessa forma, gerou-se uma mudança estrutural na cadeia produtiva do leite e o seu modelo de produção atual.

Os diferentes atores desta cadeia produtiva estão vivenciando uma crise econômica em que estão sendo forçados a tomar atitudes drásticas para garantir a sobrevivência na atividade. Essa situação autentica o debate desta cadeia, começando pelo produtor rural e sua estrutura montada, onde administra, com conhecimentos muitas vezes ínfimos, uma indústria de leite que torna-se a sua propriedade, funcionando 24 horas por dia e o ano todo. O transportador, com a incumbência de levar o produto em segurança e mantendo aos padrões de qualidade, recolhendo geralmente a noite o produto. As cooperativas que estão geralmente mais próximas dos produtores, sendo que algumas industrializam. A indústria, assim como as cooperativas que industrializam buscam colocar o mais rápido possível o leite no atacado. Por fim, chegasse ao consumidor final um produto rico ao consumo humano.

Colocado dessa maneira, esse estudo tem o objetivo socializar informações debatidas na Região Celeiro sobre a cadeia de produção do leite. Em sua estrutura, contempla primeiramente no referencial teórico um histórico da cadeia leiteira na Região Celeiro, a estrutura e mudanças na cadeia produtiva do leite, o processo de comercialização de produtos lácteos e os fatores relevantes na dinâmica da cadeia produtiva do leite. Na sequência são descritos alguns estudos realizados na cadeia produtiva do leite na Região Noroeste do RS e Oeste de SC, em seguida tem-se as considerações finais.

\section{Histórico da cadeia leiteira na Região Celeiro}

O histórico do leite na região conta com algumas fases distintas, pois em meados dos anos 80 a pecuária leiteira estava se desenvolvendo na região e, conforme relatos de leiteiros, a coleta do leite era feita com tarros de ferro numerados e eram dispostos na carroceria de um caminhão para levar aos postos de resfriamentos localizados nas cooperativas da região, (Cotricampo e Cotrimaio), que compravam o leite e repassavam o mesmo à indústria. Alguns agricultores tinham tarro de leite na propriedade para o armazenamento do produto até o leiteiro recolher e, a grande maioria, entregava em torno de 10 a 20 litros de leite por dia.

Nos anos 90 apareceram os primeiros caminhões com tanque a granel para coletar o leite no interior e já vieram algumas exigências por parte das cooperativas orientando os leiteiros que, em propriedades 
com menos de 50 litros dia o recolhimento deveria ser suspenso. Começou então a era do resfriamento do leite como solução nas propriedades, pois os leiteiros não passariam todos os dias nas propriedades para carregar o leite, e sim, a cada dois ou quatro dias, dependendo do volume.

Para o processo de resfriamento o leite era posto dentro de baldes em congeladores normais existentes nas propriedades junto com outros alimentos perecíveis como a carne. Alguns conseguiam adquirir a primeira inovação em termos de resfriamento que foram os resfriadores próprios para resfriar o leite por imersão, ou seja, o leite era armazenado dentro dos tarros e era colocado dentro da água fria para gelar e deveria ser agitado ou mexido ao menos duas vezes por dia para não congelar e a nata se separar do leite.

$\mathrm{Na}$ época o governo tinha uma estratégia para aumentar a produção de leite "fora de época", pois no inverno a produção de leite diminuía e faltava leite no mercado. Tendo um preço diferenciado do "leite cota", a estratégia era chamada de "leite extra cota" com alguns parâmetros de valor a mais pago por litro de leite conforme o aumento extra da produção.

Essa iniciativa buscava estimular a produção nos períodos de pastagens com baixa qualidade, necessitando ter um maiores investimentos na nutrição animal a base de suplementos aumentando os custos de produção. Tal estratégia pendurou por alguns anos, mas fracassou devido, entre outros fatores, a um descontentamento dos produtores por não conseguir formar cota $\mathrm{e}$ devido ao preço do leite extra cota ser $25 \%$ menor que o preço do leite cota-consumo.

No final dos anos 90, as principais empresas atuantes no recolhimento de leite eram a Elegê e Parmalat que gradativamente buscavam uma maior produtividade dos produtores de leite e excluindo aqueles que não atendiam as exigências mínimas no tocante quantidade de matéria prima por entrega. Nesse momento alguns produtores, incentivados principalmente pelos sindicatos (STR), prefeituras e leiteiros que buscavam uma saída para os pequenos produtores entregar o leite produzido, começaram entregar coletivamente a sua produção formando grupos para vender em conjunto e conseguindo adaptar-se à nova realidade nos diversos aspectos que a logística e o mercado impôs.

Com o passar dos anos, as cooperativas agrícolas, que intermediavam o leite que seria entregue a indústria, entenderam que não era viável a venda em grupo e os grupos foram acabando aos poucos. Corroboraram para isso o valor pago pelas cooperativas que estava se elevando devido à quantidade de entrega dos grupos, sendo mais vantajoso a entrega individual e o pagamento diferenciado, alguns problemas entre pessoas do mesmo grupo questionando já a qualidade do leite, o 
pagamento de vários produtores entrando na conta de um do grupo, a sanidade dos animais, o cuidado na higienização da ordenha, entre outros.

Assim, no mesmo ano de 2000 foi fundada a Central de Cooperativas Celeiro Ltda (CCCL), com a finalidade de estabelecer uma alternativa na comercialização do leite produzido pelos agricultores, sendo formada por seis pequenas cooperativas em três municípios, sendo 3 em Três Passos, 2 em Bom Progresso e 1 em Esperança do Sul.

Conforme Basso (2004), a partir de setembro de 2001, mais uma cooperativa singular se constitui e se torna associada da CCCL. Trata-se da Cooperfamiliar, com sede no município de Tenente Portela, com 150 associados e uma produção mensal de 138.965 litros. No ano de 2007 a CCCL encerrou suas atividades devido a problemas com o baixo rendimento na produção de derivados do leite entregue pelos associados, o baixo preço do leite pago ao produtor rural e também problemas de gestão. Entre as cooperativas que eram associadas a CCCL sobrou a Cooperfamiliar que se mantém atuante na região.

\section{Estrutura e mudanças na cadeia produtiva do leite}

A cadeia de derivados lácteos passou por um processo de mudança estrutural em 1991, quando o governo federal deixou de controlar os preços aos produtores e consumidores, também ocorreu a abertura do mercado brasileiro aos derivados importados, notadamente aqueles vindos da Argentina e do Uruguai, por conta do estabelecimento de uma área de livre comércio, o Mercosul. Um dos principais atores para expansão do mercado foi a comercialização do leite Longa Vida, produto que alterou e ampliou as fronteiras de produção, antes representadas por mercados regionalizados, principalmente para o leite fluido. Há mesma época se menciona o processo de granelização da coleta de leite nas fazendas, encetado aspecto tecnológico ao setor leiteiro no país (CEPEA, 2000).

Zylbersztajn (2000) divide as cadeias produtivas agroindustriais nos subsistemas: produção; transformação; distribuição e consumo. Devido ao conceito de agribusiness considerar o consumo como uma parte do sistema, sendo que este pode dar forma a toda a cadeia, pois são os estímulos dos consumidores que podem transformar os segmentos que o antecedem. Conforme o autor, no conceito de sistema agroindustrial deve-se perceber que as relações verticais de produção entre todos os segmentos da cadeia produtiva servem de balizadores para a formulação de estratégias empresariais, assim como institucionalizadores para a formulação de políticas públicas. 


\section{Processo de comercialização de produtos} lácteos

Para Barros (2006), a comercialização é um processo social de interações entre agentes econômicosno mercado. Estudos na região Noroeste do Estado ressaltam a importância e a necessidade de se fomentar a cadeia do leite, pois é uma atividade em ascensão e a comercialização do leite oportuniza uma renda mensal aos agricultores familiares para mantê-los na área rural. $\mathrm{Na}$ atividade leiteira uma parcela significativa das famílias utiliza a mão de obra familiar disponível, não tem funcionários, não investe em matrizes de genética e não amplia ou investe nas suas instalações alocando novas tecnologias.

A dinâmica de mercado nos últimos anos vem atuando no sentido de selecionar os produtores de leite por meio de critérios, como a escala de produção que classifica os produtores por pequenos, médios ou grandes; a qualidade de matéria prima baseada em controles de qualidade; serviços de inspeção sanitários adequados e profissionalismo na gestão dos negócios, que consistem no uso da tecnologia, especialização, produtividade e controles zootécnicos e econômicos que propiciem desenvolvimento à atividade (BORTOLETO; SLVA, 2001).

No contexto do mercado, o Brasil é um dos países que mais importa produtos lácteos. No entanto, para se tornar exportador para países com maior valor agregado, a qualidade do leite é um fator determinante e precisa ser melhorada. "Quando exportamos lácteos, os países de destinos foram à Venezuela, países africanos e do Oriente Médio, que são países pouco exigentes em qualidade" [...] "precisamos suprir a demanda interna, reduzindo a importação e mudando a balança comercial de lácteos a nosso favor" (ZOCCAL, 2013 p. 1).

O principal desafio colocado para a atividade leiteira no futuro é de consolidar a presença do Brasil no mercado internacional como exportador de produtos lácteos. Além de encontrar potenciais compradores interessados na aquisição dos produtos brasileiros é preciso desenvolver a produção nacional no sentido de atender as normas gerais sanitárias e de qualidade do mercado mundial e específicas de cada país importador. Esse esforço já foi iniciado há bastante tempo, mas ainda está distante de atingir os patamares necessários para ocupar fatias mais expressivas do mercado (TRENNEPOHL, 2011, p. 180).

Para Carvalho, Carneiro e Stock (2006), o Brasil é um importante produtor mundial de leite e sua produção vem apresentando crescimento contínuo como a sua oferta acima da média mundial, logo, possui condições para se tornar um grande exportador de lácteos, caso incremente as vendas para países como os do continente africano, Oriente Médio, parte da Ásia, México, Rússia e países vizinhos. 


\section{Fatores relevantes na dinâmica da cadeia} produtiva do leite

Segundo Castro et al. (1998), a nutrição do rebanho foi apontada como um dos fatores mais importantes para o desempenho da produção leiteira. Para os autores, existem alguns fatores para a baixa produtividade do rebanho leiteiro do Estado do Rio Grande do Sul, a qual se deve principalmente à alimentação inadequada, tanto em quantidade quanto em qualidade. Aliado a isto, é comum não se alimentar o rebanho segundo seu potencial produtivo individual e tanto as vacas pouco produtivas quanto as mais produtivas acabam recebendo o mesmo tratamento alimentar, fato que não otimiza a produção e ainda eleva seu custo. Salienta-se também, que boa parte dos gastos com atendimento veterinário poderiam ser evitados se os animais recebessem alimentação correta. Consequentemente, os custos de produção seriam reduzidos.

A busca por estabilidade nas relações entre a indústria e fornecedores é o principal desafio das empresas, pois as constantes disputas por preço e quantidade desestabilizam as relações e afetam a regularidade do fornecimento do leite, prejudicando a competitividade no mercado consumidor. Se, por um lado, a procura por matéria-prima é altamente disputada, principalmente aquela produzida com baixos custos, por outro os custos de transações e a produção em escala são fatores decisivos na competitividade da cadeia produtiva. Tendo garantido matéria-prima em larga escala, à medida que incorpora inovações técnicas e organizacionais, o cooperativismo vê-se novamente diante de uma grande oportunidade para competir no mercado do leite (SCHUBERT; NIEDERLE, 2009).

O processo de formação do preço do leite não segue um indexador e isso torna o mesmo questionável, pois é formado individualmente, facilitado pela ausência de parâmetros onde os agricultores não possuem clareza de como a empresa chegou a um determinado preço, muito menos dos preços pagos para os outros fornecedores da mesma empresa. Essa é uma característica de risco moral descrita por Possas, Fagundes e Pondé (1998), quando uma das partes da transação adota atitudes que prejudicam a avaliação do negócio por parte dos outros agentes envolvidos. Devido à assimetria de informações o processo torna-se mascarado e com legalidade duvidosa junto aos agricultores.

\section{Estudos realizados na cadeia produtiva do leite na Região Noroeste do RS}

Belato (1985) realizou um estudo com o objetivo de discutir a questão da integração na agricultura e a dinâmica de transformação do campesinato de tal sistema. Nas suas discussões, ressalta a ação do capital sobre a agricultura, a concentração nos segmentos a 
montante e a jusante da produção, e a transformação do campesinato expressa na destruição irreversível de suas formas históricas de organização e produção, sendo seguida pela expulsão da população excedente do campo gerando o êxodo rural e a miséria nas periferias urbanas.

O estudo traz também ao debate questões relativas a dinâmica do capitalismo com a oligopolização das empresas agroindustriais. Os agricultores tornam-se parte do elo do sistema capitalista quando compram os insumos da indústria fornecedora (a montante), e fornece a matéria-prima à indústria compradora (a jusante), e a integração de alguns agricultores elevam os níveis de produção da cadeia e os nãointegrados ficam com sérias dificuldades para se manter num sistema independente de produção e dependente na comercialização através dos oligopólios atuantes a jusante da cadeia produtiva.

As conclusões do estudo dão conta de que o capital subverte o campesinato de diferentes formas. Algumas das possibilidades seriam através da estratégia da extensão rural e do controle da geração e difusão da tecnologia agrícola e pecuária. No que tange a extensão rural, houve uma dupla permissão sobre o campesinato, enquanto difusão de uma ideologia comunitária com certas fragilidades devido a intervenção direta das agências imperialistas associadas com agências ou agentes do estado receptor, o que dava condições de penetração, por etapas, dos componentes capitalistas.

No que se refere as questões do contexto tecnológico da agricultura e pecuária, estariam sob rígido controle e eram canalizadas para uma única alternativa de desenvolvimento das forças produtivas no sentido de enquadra-las nas perspectivas e interesses oligopolizados da indústria de máquinas e insumos.

Esse controle tecnológico com direção única torna-se hegemônico quando os Estados nacionais trabalham as políticas de pesquisa e de produção agropecuária para a produção de alimentos e matérias-primas seguindo o caminho capitalista do agribusiness. Na teoria do agribusiness aflora as novas formas de divisão do trabalho em todo i universo da produção, distribuição e consumo da agricultura e pecuária, bem como as novas funções que a agricultura deve exercer no contexto do capital monopolista.

Essa teoria fornece os fundamentos da divisão da produção agropecuária em cadeias verticais coordenadas que são hegemonizadas em algum lugar, por um ou mais segmentos da cadeia situados a montante e a jusante. Assim, é a essa forma plena e total de articulação da agricultura ao capital que se chama integração, sendo o ponto ótimo de valorização do capital em que o camponês vai se alinhando a nova forma de produção, deixa de ser camponês em sua dimensão histórica para se tornar um integrado, um trabalhador 
totalmente novo, criação do capital e para o capital.

Basso (2004), estudou o desenvolvimento local e estratégias de reprodução das famílias rurais no noroeste do estado do RS. As razões que motivaram tal estudo se baseiam primeiramente na constatação de que, apesar do crescimento tecnológico alcançado no início do século XXI, a humanidade ainda convive com grandes desigualdades sociais. Também pelo surgimento de novas propostas teóricometodológicas para estudar realidades concretas que contemplam novos procedimentos levando em consideração questões políticas, institucionais e culturais, para captar e explicar mais coerentemente as situações reais de desenvolvimento, respeitando a complexidade, diversidade, incerteza e contradições presentes nas realidades observadas.

A conclusão é de que existe um número crescente de famílias que não têm conseguido garantir a sua reprodução com base no resultado exclusivo das culturas e criações que desenvolve tanto para fins comerciais como para o autoconsumo. O estudo também permitiu identificar que uma parcela da população rural local se sente à margem dos processos econômicos, sócia, culturais e políticos, apesar de se tratar de território com forte presença de iniciativas públicas e privadas que, em nível das intenções, estariam voltadas para a inclusão social, buscando melhorar as condições de vida, reduzir as desigualdades e preservar os recursos naturais.

Breitenbach (2008), fez um estudo sobre as estruturas de mercado de fatores e governança na cadeia produtiva do leite, que se realizou no município de Ajuricaba-RS. O estudo salienta que a estrutura de mercado de fatores que predominou por muitos anos na cadeia produtiva do leite, nas diferentes regiões do estado do Rio Grande do Sul, foi a de monopsônio, em que, apesar de existirem várias empresas processadoras de leite, essas se localizavam de maneira que o agricultor não tinha mais do que uma opção de venda do seu produto. De 2004 em diante, houve um significativo aumento no número de empresas processadoras de laticínio no Norte do estado do RS, um oligopsônio concorrencial, que se concentrou nas regiões que possuem fortes bacias leiteiras e gerando, consequentemente, aumento da concorrência para aquisição da matéria-prima leite in natura.

Esse estudo conclui que a concorrência no local gerou modificações no comportamento dos agentes e aumento nos custos de transação, caracterizados pela maior frequência nas transações, aumento da incerteza e do oportunismo. Já a estrutura de governança adotada na estrutura de oligopsônio, comparada à adotada no ambiente de monopsônio, continuou híbrida, mas ficou mais próxima de uma governança via mercado. $\mathrm{O}$ fator preço era o único 
definidor para a venda da matéria-prima com negociações mensais. Esse ambiente de oligopsônio foi entendido como positivo, pois os preços melhoraram, assim como o sistema produtivo que ganharam novas tecnologias e maior atenção da mão de obra familiar, com retorno de jovens ao campo devido ao resultados financeiros positivos.

Para as empresas o leilão mensal não era interessante, pois não tinha garantia da quantidade de matéria-prima disponível. Os preços pagos aos produtores de forma diferenciada geraram um clima de desconfiança na relação produtor/empresa. Tal leilão diminuiu a cobrança por qualidade do leite por parte das empresas e corroborou para a ausência de preocupação por parte dos produtores, com algumas exceções daqueles que, com a melhor remuneração, investiam em melhores instalações visando uma melhor qualidade.

Conclui também que existia, por parte dos agentes, uma preocupação de curto prazo com negociações mensais, aliada à forte concorrência no setor industrial e mercado varejista que proporcionava um comportamento oportunista de ambas as partes. A pesar de um alto grau de incerteza e alta frequência nas transações e o ativo sendo específico, não foi observado estrutura de governança baseadas em contratos formais. Isso ocorre devido ao segmento da indústria ditar as regras na negociação, sendo o articulador estratégico da cadeia. Por outro lado, os produtores defendem a liberdade comercial e por isso não tem interesse em estabelecer relações mais formais.

Trennepohl (2011), fez uma avaliação da contribuição potencial das principais atividades agropecuárias para o desenvolvimento econômico da Região Noroeste do RS, e o que elas representam enquanto propulsoras do desenvolvimento regional. O estudo identificou a importância que tiveram a triticultura e a sojicultura para o desenvolvimento da região nas últimas décadas do século $\mathrm{XX}$ e a possibilidade de diversificação da base exportadora aproveitando o potencial de contribuição que representam a pecuária leiteira, a suinocultura e a avicultura que alcançaram os padrões de competitividade nos mercados externos. Considerando que as relações sociais de produção estão em permanente transformação, alterando continuamente as condições de competitividade é de fundamental importância para o desenvolvimento de uma região a capacidade empreendedora de seus agentes econômicos e a competência de seus sistemas de inovação.

Tal estudo faz uma análise das características de culturas e atividades presentes na região noroeste e o seu grau de contribuição no desenvolvimento. Os resultados da pesquisa apontam para o fato de que a cultura da soja já fez sua contribuição para o desenvolvimento regional através dos estímulos que proporcionou para a 
modernização tecnológica da agropecuária regional nas décadas passadas e dos impulsos decorrentes para a expansão das atividades industriais e de serviços. As perspectivas de futuro apontam para uma diminuição da capacidade competitiva da região no mercado da soja, considerando que o seu efeito multiplicador é relativamente baixo, diante dos avanços verificados em outras regiões do país e uma série de limites para a expansão dos volumes e valores de produção local.

A pecuária leiteira é outra atividade econômica identificada como sendo de grande importância na região. Novos capitais, que se somam aos que já estão em operação, estão realizando investimentos de grandes proporções na ampliação da capacidade produtiva da região, especialmente focados no mercado internacional de queijos, leite em pó e outros produtos lácteos. A atividade leiteira é tradicional na região e isso lhe dá um potencial para ocupar os espaços de mercado, sendo que o leite tem um efeito multiplicador interessante para o desenvolvimento de diferentes setores da economia regional.

A suinocultura integrou da dieta da população regional e forneceu a banha como mercadoria utilizada na obtenção de renda monetária para o pagamento dos lotes pelos colonos. A suinocultura colonial entrou em crise nos anos 1950, junto com todo o modelo produtivo da época, e ressurgiu nos anos 1980, com outros parâmetros tecnológicos e de organização da produção. Grandes empresas organizaram os sistemas integrados de produção, através dos contratos de integração, fornecendo todo $\mathrm{o}$ pacote tecnológico e o cronograma de produção, em conformidade com o seu planejamento de mercado. Em novas condições, a suinocultura retoma um grau de importância e se apresenta com boas perspectivas de ser uma alternativa de diversificação da base exportadora da região.

A avicultura representa um potencial como alternativa de diversificação da base exportadora regional. Sem a necessidade de deslocar outras atividades agropecuárias existentes, poderá contribuir para a intensificação da densidade econômica da região pela geração de montantes significativos de Valor Bruto em unidades de produção que não dispõem de grandes áreas de terra disponível e, ainda, estimular o desenvolvimento de atividades complementares. As características de seu sistema de produção, com a presença de grandes empresas exportadoras que organizam todo o processo produtivo, estabelecem contratos de integração, fornecem o pacote tecnológico e fazem o planejamento de mercado, são apontadas como fundamentais para a atividade se constituir numa nova potencialidade econômica da região.

Baseado na perspectiva dos estudo de Douglass North, a diversificação da base exportadora da região é de vital importância 
para a sustentabilidade do crescimento no longo prazo. A especialização econômica em uma única atividade só é aceitável num período inicial de desenvolvimento da região em que não há possibilidades de alcançar a competitividade em mais setores. A ampliação do leque de especializações (multiespecialização) é possível a partir do desenvolvimento de atividades subsidiárias ou complementares e que alcançaram os padrões de competitividade nos mercados externos, como é o caso da pecuária leiteira, da suinocultura e da avicultura na região.

Conclui que é preciso considerar que as relações sociais de produção estão em permanente transformação, alterando continuamente as condições de competitividade. Assim, é de fundamental importância para o desenvolvimento de uma região, a capacidade empreendedora de seus agentes econômicos e a competência de seus sistemas de inovação. Estar sempre atento para descobrir novos mercados, encontrar novas fontes de matéria-prima, elaborar novos produtos e mercadorias diferenciadas, criar novos métodos de produção ou articular novos arranjos organizacionais são virtudes decisivas dos empreendedores para o desenvolvimento de seus negócios. É preciso manter a competitividade nos setores consolidados e aproveitar oportunidades que se apresentam para obter capacidade competitiva em novos segmentos.
Zagonel et al. (2015), estudaram uma iniciativa pioneira no uso de contratos na cadeia produtiva do leite na cidade de Chapecó, em Santa Catarina (SC), relatando os pontos positivos na adoção dos contratos entre a Cooperativa Agroindustrial Alfa (Cooperalfa), e os produtores. Também relatam as dificuldades enfrentadas no processo de implantação de tais contratos, pois com tradição há mais tempo na área de grãos e outros setores, por solicitação dos associados, a Cooperalfa passou a atuar na área do leite, adquirindo $\mathrm{o}$ produto $\mathrm{e}$ repassando à indústria da Cooperativa Central Aurora Alimentos, uma cooperativa central da qual, juntamente com outras 12 cooperativas, faz parte. A Cooperalfa iniciou com contratos na área do leite no final de 2011, sendo uma experiência pioneira no oeste catarinense e desde então vem procurando aperfeiçoá-la.

Os referidos contratos de integração apresentam características próprias, até mesmo pela ausência ainda de uma legislação nacional sobre o tema, constituindo-se, na prática, como contratos bilaterais entre cooperativa e produtores, sem histórico de execução jurídica dos mesmos exceto, talvez, em casos envolvendo fraudes. Neste sentido, os contratos têm tido uma função mais de "força moral" e de incentivo à fidelização dos produtores e busca por melhorias produtivas e na qualidade do leite, aspectos onde já se verificam resultados positivos após a 
implantação dos contratos (ZAGONEL et al., 2015).

Inicialmente, os contratos foram apresentados aos produtores de maneira voluntaria onde, inclusive, a cooperativa bonificou quem o aderiu. Essa medida estimulou a aceitação dos produtores, onde cerca de 95\% aderiram aos contratos. Para produtores novos, os contratos são compulsórios. Dentre outros mecanismos utilizados na formação dos preços pagos ao leite dos produtores há uma política de metas de qualidade associada aos contratos, onde quem as atinge na plenitude pode ter até $15 \%$ de bonificação.

Essa experiência inovadora na implantação de contratos foi, paulatinamente, ganhando adesão e confiabilidade, inclusive, entre as entidades representativas dos produtores, as quais de críticas inicialmente passaram a estimular os contratos ultimamente. Neste sentido, acredita-se que os contratos de integração na atividade leiteira, a exemplo da experiência da Cooperalfa, podem auxiliar na normatização das relações entre comprador e produtor e na fidelização entre ambos, na governança e transparência do setor, em especial, na formação dos preços.

Sendo assim, a adoção dos contratos só vem a fortalecer a cadeia produtiva do leite para que haja um efetivo desenvolvimento local e regional, restaurando a confiança do consumidor ao consumo de leite e seus derivados. Nos moldes atuais, os contratos seriam mais um contrato moral por parte da cooperativa, vindo a exigi-lo integralmente somente em casos extremos de fraude, assim como o produtor também pode exigi-lo por motivos distintos. Dessa forma, os contratos são bilaterais e visam uma maior segurança nas relações entre ambas as partes.

\section{CONSIDERAÇÕES FINAIS}

Dentro do contexto abordado o apoio das diferentes entidades da região se faz necessário para que possam desenvolver ações em conjunto, de forma concreta e efetiva, buscando soluções ao diferentes problemas que afetem o setor lácteo. Com o objetivo socializar informações debatidas na região celeiro, as quais estão latentes no ambiente de crise que vive a cadeia produtiva do leite, algumas proposições tem maior destaque, como a possibilidade dos contratos de integração que especificariam os direitos e deveres de ambas as partes, trazendo uma confiabilidade ao consumidor sobre a qualidade do produto final. Também a qualificação na gestão das propriedades com assistência técnica de qualidade e não direcionada a beneficiar empresa $\mathrm{A}$ ou $\mathrm{B}$. Uma representatividade maior do setor leiteiro junto ao governo e maior atuação de associações, cooperativa e sindicatos nas questões relativas a cadeia produtiva do leite.

A união dos diferentes elos da cadeia é imprescindível sendo necessário trabalhar mais o associativismo e o cooperativismo como formas reestabelecer a confiança entre 
os atores, pois, de uma ou outra forma, todos são afetados pela crise. Essas argumentações vêm ao encontro dos estudos realizados na cadeia produtiva do leite no noroeste do RS.

Salienta-se a necessidade de um entendimento sobre a cadeia produtiva do leite e seus desafios futuros, entendendo como o mercado nacional e internacional influencia na vida do pequeno, médio ou grande produtor de leite, e o que isso interfere no desenvolvimento das regiões como um todo.

O estudo buscou socializar pontos chaves que possibilitam o desenvolvimento de uma região através das afirmações do referencial teórico e estudos realizados na região Sul do Brasil. O ambiente de crise que vive a cadeia produtiva do leite é transitório e evolutivo quando olhamos para os gargalos existentes na cadeia e mitigamos suas patologias existentes e nos preparamos para as que virão.

As mudanças na cadeia estão acontecendo no setor produtivo, industrial e comercial, levando a um processo seletivo dos elos envolvidos do setor. Com o mercado cada vez mais exigente, mais cedo ou mais tarde irá atentar não só para a qualidade dos produtos, mas também o que ele representa socialmente, economicamente e ambientalmente. A profissionalização da cadeia visando diminuir os custos, aumentar a produção por animal e uma matéria-prima de qualidade são algumas das possibilidades para aumentar a competitividade dos diferentes elos do setor lácteo.

Conforme Zylbersztajn (2000) a cadeias produtivas agroindustriais se divide em subsistemas que são de produção, transformação, distribuição e consumo. Esses são os elos principais da cadeia produtiva do leite, sendo que esta cadeia é a que mais emprega na área rural da região e cumpre um papel social e essencial na economia local e regional.

Sendo assim, o estudo conclui que sem a sinergia entre o ambiente institucional e organizacional, tais como o poder público, agricultores, laticínios locais, indústrias regionais, universidades, empresas de assistência técnica, segmentos de pesquisa, entre outras afins, não há possibilidade da região se desenvolver de forma endógena e sustentável, pois os elos são dependentes e a cooperação deve prevalecer nas diferentes fases do processo.

\section{REFERÊNCIAS}

BARROS, G. S. C. Economia da comercialização agrícola.Piracicaba: CEPEA/LES-ESALQ/USP, 2006.

BASSO, David. Desenvolvimento local e estratégias de reprodução das famílias rurais: abordagens sobre o desenvolvimento rural na região Noroeste do Rio Grande do Sul. Tese (Curso de pós-graduação em desenvolvimento, agricultura e sociedade) UFRRJ, 2004.

BELATO, Dinarte. Os camponeses integrados. Dissertação (Pós-Graduação em 
História) - Universidade Estadual de Campinas, 443f. São Paulo, 1985.

BORTOLETO, E. E.; SILVA, A. L.

Gerenciamento de sistemas agroindustriais: definições se correntes metodológicas. In: BATALHA, Mário O. (coord). Gestão agroindustrial. São Paulo: Atlas, 2001.v. 1.

BREITENBACH, R. Estruturas de mercado de fatores e governança na cadeia produtiva do leite: um estudo de caso no município de Ajuricaba-RS. 2008.113f. Dissertação (Mestrado em Extensão Rural)Universidade Federal de Santa Maria. Santa Maria-RS.

CARVALHO, G. R.; CARNEIRO, A. V.; STOCK, L. A. O Brasil no cenário mundial de lácteos. Juiz de Fora: out. 2006.

Disponível em:

<http://www.cnpgl.embrapa.br/nova/publicac oes/comunicado/COT51.pdf> Acesso em: 07 out. 2013.

POSSAS, M.; FAGUNDES, J.; PONDÉ, J. Custos de transação e políticas de defesa da concorrência. Revista de Economia Contemporânea. Volume 2, Rio de Janeiro, 1998.

SCHUBERT, M. N.; NIEDERLE, P. A.

Estratégias competitivas do cooperativismo na cadeia produtiva do leite: o caso da Ascooper, SC. In: CONGRESSO DA SOCIEDADE BRASILEIRA DE ECONOMIA, ADMINISTRAÇÃO E SOCIOLOGIA RURAL, Porto Alegre, 2009.

TRENNEPOHL, Dilson. Avaliação de potencialidades econômicas para $o$ desenvolvimento regional. Ijuí: Unijuí, 2011.

ZAGONEL, Tiago Reginaldo; TRENNEPOHL, Dilson; AMARAL, Volmir Ribeiro do; BASSO, David. CONTRATOS NA CADEIA PRODUTIVA DO LEITE COMO FORMA DE FORTALECÊ-LA: UM CASE PIONEIRO EM SANTA

CATARINA. Anais-Seminário

Internacional sobre Desenvolvimento

Regional, 2015.
ZOCCAL, R. Produção de leite no Brasil ainda é deficitária. Disponível em: $<$ http://www.brasilvitrine.com/clique/index.p hp?n_id=5281\&u=ProducaodeleitenoBrasilai ndadeficitaria/ > Acesso em: 18 Out. 2013.

ZYLBERSZTAJN, D. Conceitos gerais, evolução e apresentação do Sistema Agroindustrial. In: ZYLBERSZTAJN, D.; FAVA NETO, D.(org). Gestão dos negócios agroalimentares: indústria de alimentos, indústria de insumos, produção agropecuária. São Paulo. Pioneira, 2000. 